\title{
Interleukin-6 inhibition in the management of non-infectious uveitis and beyond
}

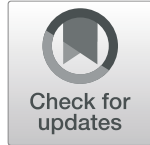

\author{
Samendra Karkhur ${ }^{1,2}$, Murat Hasanreisoglu ${ }^{1,3}$, Erin Vigil ${ }^{1,4}$, Muhammad Sohail Halim', Muhammad Hassann', \\ Carlos Plaza ${ }^{1,5}$, Nam V. Nguyen ${ }^{1,6}$, Rubbia Afridi ${ }^{1}$, Anh T. Tran', Diana V. Do ${ }^{1}$, Yasir J. Sepah ${ }^{1}$ and \\ Quan Dong Nguyen ${ }^{1 *}$
}

\begin{abstract}
Background: Uveitis consists of a spectrum of inflammatory disorders characterized by ocular inflammation. The underlying pathophysiology consists of a complex interplay of various inflammatory pathways. Interleukin 6 is an important mediator of inflammation in uveitis and constitutes focus of research toward development of newer biological therapies in the management of non-infectious uveitis.
\end{abstract}

Main body: Pan-blockade of the inflammatory pathways with steroids is generally the first step in the management of acute non-infectious uveitis. However, long-term therapy with steroids is associated with systemic and ocular side effects, thereby necessitating the need for development of steroid sparing agents. IL-6 is a cytokine produced by various immune cells, in response to molecular patterns and affects multiple inflammatory cells. In particular, IL-6 is involved in differentiation of CD-4 cells into Th-17 cells that have been shown to play a significant role in various immune-mediated diseases such as uveitis. This broad-spectrum immunomodulatory activity makes IL-6 an excellent target for immunomodulatory therapy. Tocilizumab was the first IL-6 inhibitor to demonstrate efficacy in humans. It inhibits IL-6 from binding to both membrane-bound and soluble receptor and can be administered via intravenous (IV) and subcutaneous (SC) routes. It has been FDA approved for treatment of rheumatoid arthritis (RA) and juvenile idiopathic arthritis (JIA). Following the approval in systemic diseases, its efficacy was demonstrated in various uveitis studies including a phase 2 clinical trial (STOP-Uveitis). Overall, tocilizumab has shown a good safety profile with the risk of malignancy consistent with that expected in patients with rheumatoid arthritis. However, tocilizumab therapy has been shown to increase the risk for gastrointestinal perforation and dose-dependent neutropenia. Following the success of tocilizumab, several other agents targeting the IL- 6 pathway are in the pipeline. These include sirukumab, siltuximab, olokizumab, clazakizumab, and EBI-031 which target IL-6; Sarilumab and ALX-0061 act on the IL-6 receptor.

Conclusion: Studies have shown that IL-6 inhibitors can be effective in the management of NIU. In addition, the levels of IL-6 are elevated in other ocular vascular diseases such as retinal vein occlusion and diabetic macular edema. The roles of IL-6 inhibition may be broadened in the future to include the management of retinal vascular diseases and non-uveitic macular edema.

Keywords: Uveitis, Interleukin-6, Newer biologics, Non-infectious uveitis, Tocilizumab, Steroid-sparing therapy, Immunomodulatory therapy, Biological therapy, Interleukin-6 inhibition

\footnotetext{
* Correspondence: ndquan@stanford.edu

${ }^{1}$ Byers Eye Institute, Spencer Center for Vision Research, Stanford University,

2370 Watson Court, Suite 200, Palo Alto, CA 94303, USA

Full list of author information is available at the end of the article
} 


\section{Introduction}

Uveitis is an infectious or non-infectious inflammatory disease of the uvea and other intraocular tissues including the retina, vitreous, and lens. With an incidence of more than 50/100,000-person years, uveitis is a common cause of legal blindness in the western world [1]. In infectious uveitis, the etiology is specific, and the presentation may be characteristic of that infection, although not necessarily for syphilis, tuberculosis, and some AIDS-related opportunistic infections which may mimic many other forms of autoimmune non-infectious uveitis. However, the pathophysiology of non-infectious uveitis is not fully understood, and the etiology might be multifactorial-involving an interplay of genetic, immune, and environmental factors. Viral prodrome that is associated with the presentation of many non-infectious uveitis entities could provide a link connecting the two. Similarly, gut commensals provide a signal directly through the retinaspecific $\mathrm{T}$ cell receptor and cause autoreactive $\mathrm{T}$ cells to trigger uveitis. Microbiota may also serve as an "adjuvant" providing innate signals that amplify and direct the host immune response for development of uveitis [2].

Induction of biologic drugs in the treatment of non-infectious uveitis has introduced a new treatment modality in the field of uveitis. Basic research done in this field has paved way for newer molecules which offer a more targeted and specific therapeutic approach. Anti-TNF- $\alpha$, considered the first-line biological agent recommended in the treatment of uveitis, has proven remarkably effective. It is by virtue of rapid inflammation control and increased tolerability due to minimal, specific, and manageable sideeffects. Despite these benefits, most studies show that approximately $50 \%$ of patients with non-infectious uveitis treated with anti-TNF are unresponsive/intolerant [3]. Both physicians and patients have increased expectations from therapeutic agents and end result is not just a good control of inflammation but achieve total clinical remission early in the disease course, so that minimal sequelae result.

Non-responsiveness to TNF blockade and/or residual disease activity, as well as the ongoing, slowly progressing structural damage in a significant proportion of patients treated with TNF inhibitors suggest that-apart from TNF-there are other biological targets involved in the disease process. Interleukin 6 (IL-6) has emerged as a major player in the pathogenesis of autoimmune disease and chronic inflammation. Infection and inflammation cause significant upregulation of IL-6, which features pleiotropic activity and mediates various biological functions. It causes induction of acute-phase reactants in liver, $\mathrm{T}$ cell differentiation, regulates inflammatory cells, homeostasis, and healing after tissue injury [4]. Various systemic autoimmune diseases and certain types of cancers have been associated with dysregulation in IL-6 production [5]. In cases of diabetic macular edema, retinal vein occlusion, and chronic uveitis, IL- 6 has been found to be significantly elevated in ocular fluids $[6,7]$. In the past decades, tocilizumab, a monoclonal antibody (mAB) which targets IL-6 receptor (IL-6R), has been investigated and approved for therapeutic use in a number of immunologic diseases. Several clinical trials have reported it to be effective for the treatment of uveitis and associated macular edema [8-11].

\section{IL-6 biology: mechanism of action}

Human IL-6 is a $26 \mathrm{kDa}$ protein made up of 212 amino acids codified by a gene located in chromosome 7 p21 [12]. IL-6 triggers signal transduction after binding the IL-6 receptor (IL-6R). There are two forms of IL-6R: the $80 \mathrm{kDa}$ transmembrane receptor protein and the $55 \mathrm{kDa}$ soluble form (sIL6-R). It is believed that the pleiotropic effect of IL- 6 derives from the broad range of cells expressing gp130. IL-6 plays an important role in protecting the host against environmental insults and sends out warning signals through all systems of body about the occurrence of acute events. Physiological levels of IL-6 are very low (1-5 pg/ml) and hardly detectable in serum, but the levels can increase $>100,000$-fold during acute inflammatory response [13].

Different cell types in the body produce IL-6, including cells of innate immune system such as neutrophils and monocytes/macrophages. IL-6 is important in the integrated host defense against numerous pathogens including bacteria, fungi, viruses, and mycobacteria [14]. When these infectious pathogens stimulate Toll-like receptors (TLRs) by producing pathogen-associated molecular patterns (PAMPs), they result in prompt production of IL-6 by monocytes and macrophages. In non-infectious inflammation such as during burns and trauma, the affected cells produce damage-associated molecular patterns (DAMPs) which in turn stimulate TLRs, to produce IL-6 [15]. Expression of inflammatory cytokines such as IL-6, TNF- $\alpha$, and IL-1 $\beta$ is upregulated through various signaling pathways initiated by PAMPs and DAMPs. TNF- $\alpha$ and IL- $1 \beta$ in turn can activate transcription factors to synthesize IL-6 [16].

IL-6 stimulates hepatocytes to induce synthesis of acutephase reactants like C-reactive protein (CRP), fibrinogen, haptoglobin, alpha-1-antichymotrypsin, and serum amyloid A. CRP is a consistent biomarker of inflammation and is often employed to monitor various inflammatory processes. Its expression mainly depends on IL-6 [17]. Persistent elevation of alpha-1-antichymotrypsin and serum amyloid A has been associated with the pathogenesis of Alzheimer's disease [18].

Reduced serum iron levels have been reported secondary to IL-6-mediated hepcidin production; latter exerts antagonistic action on the iron transporter ferroportin-1 in intestinal epithelium. This IL-6-hepcidin interaction might be responsible for the anemia found in chronic inflammatory states [19]. IL-6 also upregulates the 
expression of ZIP 14 (zinc importer), which results in low levels of zinc in chronic inflammation. IL-6 downregulates the expression of fibronectin, albumin, and transferrin. This change in acute-phase reactants is routinely used in clinical laboratory tests for detection of inflammation.

In addition to its role in host defense, IL-6 mediates various biological functions. IL- 6 induces activation of stem cells and helps megakaryocytes' maturation into platelets during hematopoiesis [20]. In bone marrow, IL-6 upregulates the receptor activator of nuclear factor kappa$B$ ligand (RANKL), which in turn leads to bone resorption and osteoporosis by activating osteoclasts [21].

Production of IL-6 in inflamed tissues upregulates vascular endothelial growth factor (VEGF), which results in increased angiogenesis and vascular permeability [22]. IL-6 promotes proliferation of dermal keratinocytes, and collagen production by fibroblasts, which may contribute to the pathogenesis of diseases like psoriasis, systemic sclerosis, and thyroid eye disease [23].

\section{IL-6 receptors and signaling pathways}

Interleukin 6 plays an important role in host defense against environmental stress such as infection and injury. Dysregulated IL-6 production has been implicated in the development of various autoimmune diseases and chronic inflammatory diseases. IL-6 is a prototypical four-helix bundle cytokine that is a member of the neuropoietins, which includes IL-6, IL-11, IL-27, IL-31, leukemia inhibitory factor, oncostatin $\mathrm{M}$, cardiotrophin-1, neuropoietin, and neurotrophin-1 [19]. These cytokines are structurally related and bind to Class I cytokine receptors. With the exception of IL-31, all IL-6 type cytokines share the membrane glycoprotein gp130 as a common beta receptor and signal transducer subunit [24, 25].

IL-6 signaling occurs through two cellular pathways: the classical and trans-pathway. In the classical signaling pathway, IL-6 binds to membrane-bound type I receptor complex consisting of the ligand-binding glycoprotein, IL-6 $\alpha$. The expression of this receptor is mostly restricted to leukocytes and hepatocytes. The IL-6/IL-6 $\alpha$ complex subsequently associates with gp130 leading to gp130-homodimer formation [26]. In trans-pathway, IL6 provides signaling to cells lacking IL-6R via binding to soluble IL-6R (sIL-6R), which is generated by alternative splicing or ectodomain shedding of the membranebound IL-6 receptor (Fig. 1) [27]. Both classical and trans-signaling pathways are gp130-mediated and activate the same intracellular pathways.

After the formation of gp130 homodimer, IL-6 initiates the intracellular signaling by activating the Janus kinase family tyrosine kinases (JAKs) [28]. Activation of these kinases leads to phosphorylation and activation of signal transducers and activators of transcription 3 (STAT3) and the $\mathrm{SH} 2$-domain containing protein tyrosine phosphatase-2
(SHP2) $[29,30]$. Phosphorylated STAT3 translocates to the nucleus and regulates transcription of various genes. SHP2 activates SOS/Ras-Raf-MEK-MAP kinase pathway to regulate genes [31].

It is important to note that the activation of STAT3 in turn induces the suppressor of cytokine signaling 1 (SOCS1) and SOCS3, which bind tyrosine-phosphorylated JAK and gp130 respectively, to stop IL- 6 signaling by means of a negative feedback loop [32, 33].

There is counter-regulation by a soluble form of gp130 (sgp130), present at high concentrations in serum of healthy individuals. As part of the physiological IL- 6 buffer in the blood, this natural inhibitor forms a complex with IL-6/sIL-6R, preventing the binding of IL-6/sIL-6R to membrane-bound gp130. This ensures that IL-6/sIL6R trans-signaling is tightly regulated [34].

Various studies have shown that classic signaling via the membrane-bound receptor is regenerative and protects from bacterial infections, whereas trans-signaling via the soluble receptor is proinflammatory [35]. Therefore, it may make sense to block only the IL- 6 trans-signaling alone, which would maintain the regenerative function of IL-6 and specifically suppress only inflammatory arm mediating the disease process (Fig. 2) [27].

\section{IL-6 and autoimmunity}

As mentioned earlier, IL-6 is a pleiotropic cytokine that plays important roles in hematopoiesis, immune defense, and oncogenesis [36]. Historically, IL-6 molecule had been studied under many different names such as $B$ cell stimulatory factor-2 (BSF-2), IFN- $\beta 2$, Hybridoma/plasmacytoma growth factor, hepatocyte-stimulating factor (HSF), until advancements in molecular testing. In the following sections, we will discuss the role of IL-6 in immune cascades and defense mechanisms, pathological significance of IL-6 signaling in inflammatory autoimmune systemic and ocular diseases, as well as therapeutic implications of IL-6 targeted therapy.

\section{Immunomodulatory role of IL-6 $B$ cells}

IL-6 was originally identified and named as B cell stimulatory factor 2 because it promotes the differentiation of activated $\mathrm{B}$ cells into plasma cells which are responsible for antibody production [36]. Interactions between $\mathrm{T}$ and $\mathrm{B}$ cells during antibody production were first reported in 1968 and it was theorized that certain molecules were released from $\mathrm{T}$ cells which stimulate $\mathrm{B}$ cells to produce antibodies [37]. B cells can produce antibodies, but not without having $\mathrm{T}$ cells producing those growth and differentiation factors. IL-6 produced by plasmacytoid dendritic cells is critical for this process [38]. IL-6 also promotes T follicular helper cell differentiation as well as production 


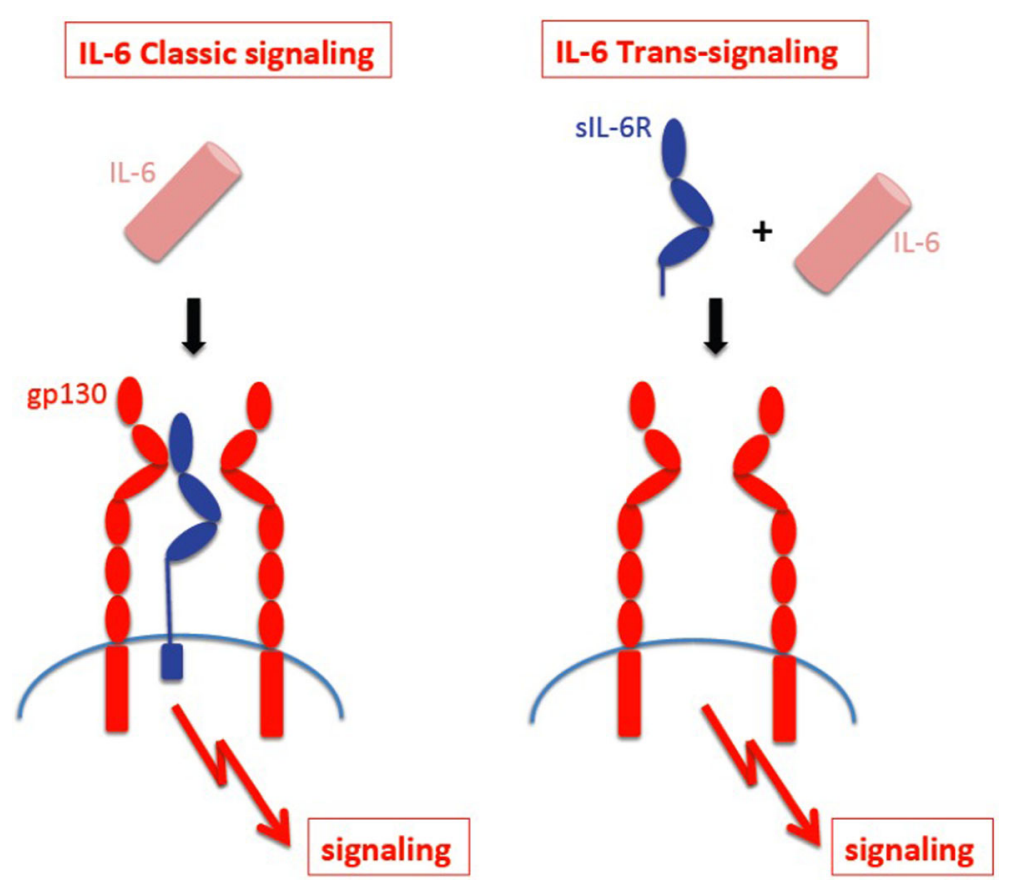

Fig. 1 IL-6 classic-signaling and IL-6 trans-signaling. IL-6 classic signaling requires membrane bound IL-6R and is restricted to hepatocytes, some epithelial cells and some leukocytes. IL-6 trans-signaling requires sIL-6R and is possible on all cells of the body since all cells express the gp130 protein. Adapted from "IL-6 trans-signaling via the soluble IL-6 receptor: Importance for the pro-inflammatory activities of IL-6." by Rose-John S, Int J Biol Sci 2012; 8:1237-1247 [Copyright: Ivyspring International Publisher]

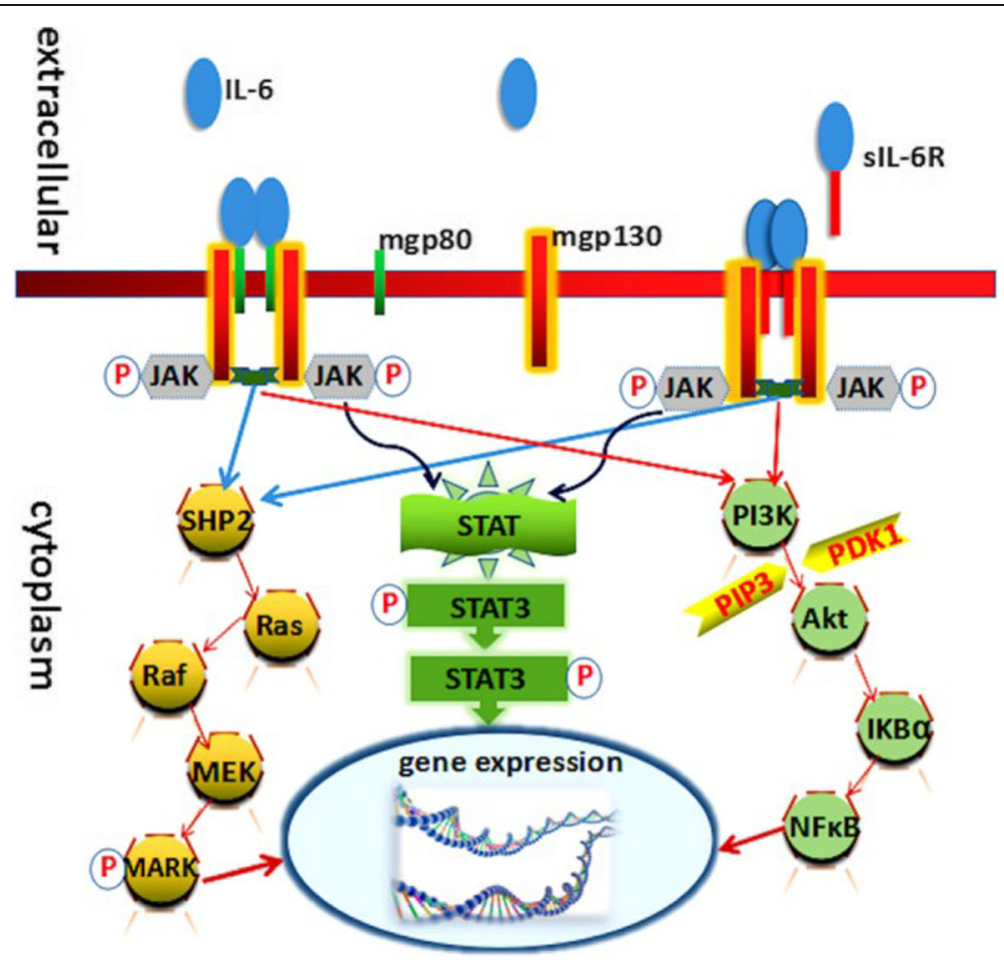

Fig. 2 Signaling, activation, and transduction pathways of IL-6. Adapted from "Hall of Fame among Pro-inflammatory Cytokines: Interleukin 6 Gene and Its Transcriptional Regulation Mechanisms." by Luo Y, Zheng SG. Immunol. 2016; 7:604. [Copyright: @ 2016 Luo and Zheng] 
of IL-21, which also promotes B cell differentiation and increase immunoglobulin synthesis [39, 40].

Moreover, IL-6 may promote the survival of the plasma blasts that secrete immunoglobulin or pathological autoantibodies, e.g., anti-aquaporin 4 in patients with neuromyelitis optica (NMO) [41]. IL-6 may act as an autocrine growth factor in some types of multiple myelomas while some others are themselves able to produce IL-6 [42].

\section{$T$ cells}

As mentioned, IL-6 was first identified as a B cell function and differentiation factor; however, $\mathrm{T}$ cell differentiation and activation is another major action of IL-6 [36]. IL-6 signaling has been found to control proliferation of resting $\mathrm{T}$ cells and reinforcing their resistance against apoptosis by inducing IL-2 production and STAT-3 activation [43]. IL-6 has also been identified as major regulator between regulatory $\mathrm{T}$ cells (Treg) and effector Th17 cells. In combination with transforming growth factor (TGF)- $\beta$, IL-6 brings about differentiation into Th17 cells, but inhibits TGF- $\beta$-induced Treg development $[44,45]$. This results in an increase of Th17 cell population over Treg cells which may have a role in altered immunological tolerance and resulting in the development of autoimmune inflammatory diseases [46].
IL-6 also modulates Th1 and Th2 balance. It enhances the production of Th2 cells by promoting IL-4 and IL-13 production [47]. On the other hand, it inhibits Th1 cell differentiation and interferon-gamma (IFN- $\gamma$ ) production [48].

\section{IL- 6 and acute-phase response}

IL-6 is a major cytokine in the initiation process of acutephase responses [36]. In the serum of healthy individuals, the IL-6 level is less than $5 \mathrm{pg} / \mathrm{ml}$; however, IL-6 concentration increases dramatically during infectious and non-infectious events [49]. IL-6 acts as an important factor in the synthesis of acute-phase proteins by the liver, such as C-reactive protein (CRP), serum amyloid A (SAA), fibrinogen, hepcidin, and $\alpha 1$-antichymotrypsin [50]. Administration of IL-6 inhibitors completely normalizes the serum levels of CRP and SAA, indicating that their synthesis depends primarily on IL6 [51]. These major acute-phase reactants act as an inducer of systemic inflammatory and infectious response. Elevated levels of CRP have been reported in serum of patients with various autoinflammatory diseases such as rheumatoid arthritis, systemic lupus erythematosus, among others, as well as bacterial and viral infections [52]. When the emergent stimuli are completely removed from the host, the IL-6-mediated signal transduction cascade is terminated, leading to normalization of the CRP level in serum (Fig. 3) [53].

\section{Pro- and Anti-Inflammatory Activities of Interleukin-6}

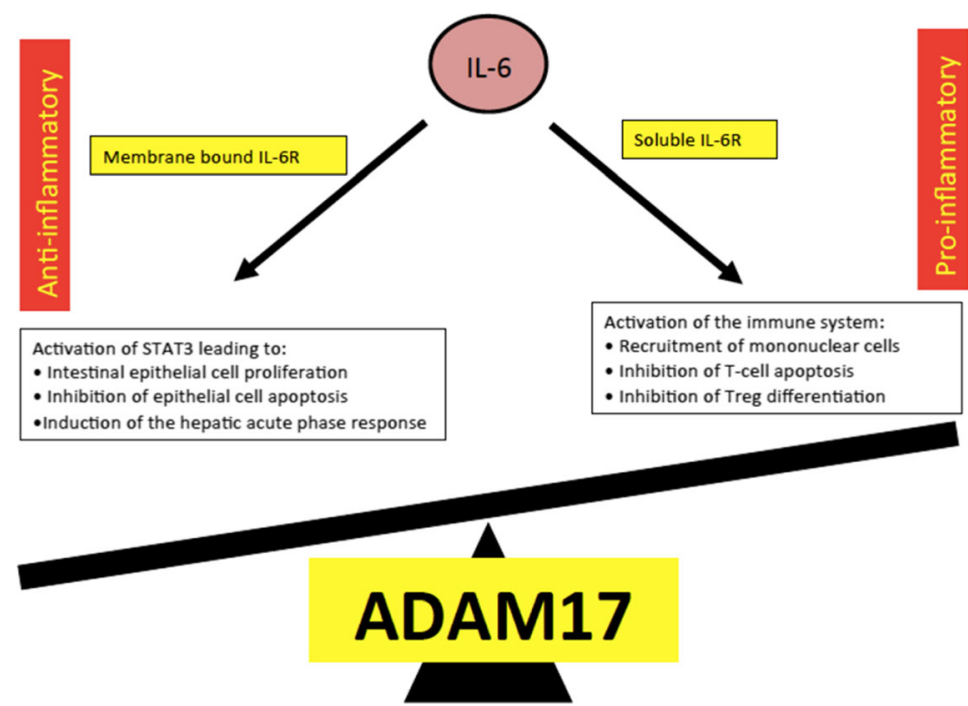

Fig. 3 Pro- and anti-inflammatory activities of IL-6. Anti-inflammatory activities of IL-6 include STAT3-dependent regeneration of epithelial cells and the induction of the hepatic acute-phase response. These activities are dependent on the membrane-bound IL-6R. Pro-inflammatory activities of IL-6 include recruitment of inflammatory cells, inhibition of apoptosis of inflammatory cells, and inhibition of regulatory T cell differentiation. Adapted from "Hall of Fame among Pro-inflammatory Cytokines: Interleukin-6 Gene and Its Transcriptional Regulation Mechanisms." by Luo Y, Zheng SG. Immunol. 2016; 7:604. [Copyright: Ivyspring International Publisher] 


\section{IL-6 regulation}

Due to the rapid plasma clearance, IL-6 levels are largely regulated at the transcriptional and post-transcriptional gene expression level [49]. The molecular aspects of IL-6 regulation comprise of complex interactions between proteins, miRNAs, and IL-6 gene expression, which is beyond the scope of this review.

\section{IL-6 in various systemic autoimmune diseases}

IL-6 was first associated with disease development in a case of cardiac myxoma, a benign heart tumor [54]. Subsequently, excessive IL-6 expression patterns were detected in several other autoimmune inflammatory diseases including chronic rheumatoid arthritis, juvenile idiopathic arthritis, systemic lupus erythematosus, AdamantiadesBehcet's disease, and systemic sclerosis [30, 50, 55, 56]. It is also known that the extent of elevation of serum IL-6 level depends on the type and severity of the disease [57]. On this basis, IL-6 inhibition strategy is currently being pursued to develop novel therapies for inflammatory pathologic conditions. The following sections will focus on IL-6 inhibitors and their usage in systemic and ocular inflammatory diseases.

\section{Experimental autoimmune uveitis-animal model}

Several experimental autoimmune uveitis (EAU) studies demonstrated the importance of IL-6 in non-infectious uveitis (NIU). In an animal model of $\mathrm{T}$ cell-mediated uveitis (interphotoreceptor retinoid binding protein (IRBP) immunization model), Yoshimura et al. showed that IL-6-deficient mice could not induce Th17 cells and the EAU score was found to be decreased in those mice in the entire time course [58]. On the other hand, systemic administration of anti-IL-6 receptor antibody reduced uveitic inflammation. This effect in EAU appears to occur via the suppression of both Th1 and Th17 differentiation, both of which are important in this animal model of uveitis. Haruta et al. induced EAU in wild-type (WT) mice and in mice lacking IL-6, IL-17, and IFN- $\gamma$ and also in IL-6-lacking mice treated with anti-CD 25 monoclonal antibody (mAb) to deplete Treg cells [59]. IL-6 deficiency resulted in the inhibition of the antigen-specific Th1 response and enhanced the generation of antigen-specific Treg cells. Authors concluded that blockade of IL-6 signaling suppresses not only Th17 but also IRBP-specific Th1 by promoting regulatory $\mathrm{T}$ cells in EAU.

\section{IL-6 in ocular pathologies and non-infectious uveitis}

IL-6 is a key cytokine which is strongly upregulated during infection/inflammation and associated with variety of systemic autoimmune diseases. Elevated levels of IL-6 have been detected in many ocular diseases such as glaucoma, central vein occlusion, dry eye disease, chemical burn injuries, corneal infections, allergic eye diseases, and ocular inflammatory diseases $[56,60]$.

Murray et al. was the first to demonstrate elevated aqueous humor levels of IL-6 in 24 human subjects with uveitis, including, Fuchs' heterochromic iridocyclitis and toxoplasma uveitis [61]. Several groups also found IL-6 to be elevated in ocular fluids including vitreous in patients with active or chronic NIU supporting its mainstream role in ocular inflammatory process $[7,62,63]$.

All these evidences, since the first report on the discovery of IL-6 in 1973 by Kishimoto and Ishizaka, have led to a pursuit of new IL-6 inhibitory drugs, for the management of pathologic inflammatory conditions including several types of NIU [64].

Vascular endothelial growth factor (VEGF) plays an important role in the pathogenesis of macular edema in central retinal vein occlusion (CRVO) and diabetic retinopathy by enhancing vascular permeability and altering retinal endothelial tight junctions. In the presence of hypoxia, IL-6 plays a major role in VEGF induction. Vitreous levels of IL-6 and VEGF correlate with the severity of ischemia and are found to be significantly elevated in patients with ischemic CRVO and correlated with the severity of disease $[65,66]$.

Elevated levels of IL-6 with other cytokines have been shown in proliferative diabetic retinopathy (PDR) wherein the progression may lead to tractional or combined mechanism retinal detachment [67]. IL-6 has also been implicated in the pathogenesis of proliferative vitreo-retinopathy (PVR) after rhegmatogenous retinal detachment (RRD). IL-6 stimulated the production of matrix metalloproteinases (MMPs) which play a major role in the development of PVR [68].

IL-6 has also been found to have a role in various other ocular diseases such as allergic conjunctivitis and dry eye disease, infectious keratitis, ocular neovascularization, and posterior capsular opacification [69-73].

\section{Non-specific anti-IL-6 drugs}

Corticosteroids The mechanism of action of corticosteroids on IL-6 inhibition is not fully understood; however, they are known to inhibit IL-6 production at the transcriptional level $[57,74]$. This process may involve suppression of gene upregulation by nuclear factor- $k \beta$ $(\mathrm{NF}-\mathrm{k} \beta)$ or by the occlusion of promotor elements in the IL-6 promotor [5]. Although corticosteroids are the mainstay treatment in many types of inflammatory diseases and IL-6 inhibition is one of their pleiotropic mechanisms of action, their dose-dependent side effects limit long-term therapeutic usage.

These effects are mediated by its specific inhibition of IkB kinase-b, which prevents activation of nuclear factor -kB (NF-kB) 
Tetracyclines Tetracyclines are broad-spectrum antibiotics that can act against a wide range of microorganisms via inhibition of protein synthesis [75]. The immunomodulatory and anti-inflammatory properties of tetracyclines suggested that this drug might be effective in the treatment of autoimmune disorders [76]. Wide spectrum anti-inflammatory effects of these drugs are thought to be partially due to suppression of IL- 6 by the blockage of NF-k $\beta$ signaling [77].

\section{Targeted biological anti-IL-6 drugs}

Tocilizumab Tocilizumab (Actemra ${ }^{\circ}$, Roche AG, Basel, Switzerland) is a humanized mouse monoclonal antibody inhibitor of IL-6 receptor. Tocilizumab (TCZ) prevents the binding of IL- 6 with its membrane and soluble receptors and antagonizes its action [4,6]. It is currently approved for the treatment of rheumatoid arthritis (RA), juvenile idiopathic arthritis (JIA), and giant cell arteritis (GCA) by the FDA [37, 78]. Apart from these, many retrospective open-label studies have shown efficacy of TCZ in inflammatory and/or autoimmune diseases refractory to conventional therapy and/or other biologics which included series of other large-vessel vasculitis (Takayasu's arteritis), Adamantiades-Behçet's disease (ABD), adult onset Still's disease, multicentric Castleman disease (approved in Japan), relapsing polychondritis, Cogan's disease, inflammatory myositis, and lupus [79].

Large randomized controlled trials (RCTs) on TCZ therapy for RA paved way for its usage in other systemic and ocular inflammatory conditions, since it provided valuable information on the efficacy and side effect profile of the drug. TCZ demonstrated therapeutic potential in moderate to severe active RA patients with inadequate response to methotrexate (MTX), or other conventional disease-modifying antirheumatic drugs (cDMARDs) or biological disease-modifying antirheumatic drugs (bDMARDs) like TNF antagonists [36, 37, 49, 50]. Also, TCZ was found to be better than MTX monotherapy, with rapid improvement in signs and symptoms in patients with active RA, for whom previous treatment with MTX/biological agents had not failed [52]. On the other hand, two phase 3 studies showed that immediate initiation of TCZ with or without MTX in early progressive RA was also more effective and associated with sustained remission and low disease activity, but with a similar safety profile compared with initiation of MTX alone $[80,81]$. The results of the phase 4 ADACTA study comparing the efficacy of TCZ $8 \mathrm{mg} / \mathrm{kg}$ monotherapy versus anti-TNF- $\alpha$ agent adalimumab monotherapy were also in favor of TCZ in terms of reduction of signs and symptoms of RA, in patients for whom MTX was deemed inappropriate [82].

Successful use of tocilizumab with an acceptable safety profile has been reported in patients with NIU who did not respond to several other treatments. In 2011, Muselier et al. reported the first two cases of refractory uveitis (birdshot chorioretinopathy (BSC) and idiopathic panuveitis) treated by tocilizumab with favorable results and acceptable short-term safety profile [83]. After that report, several case series have demonstrated efficacy of tocilizumab in the treatment of uveitis refractory to antiTNF agents $[8,84,85]$. Papo et al. in their study with eight consecutive unselected patients with severe and refractory non-infectious uveitis including BD, BSC, and idiopathic cases concluded that tocilizumab was safe and promising [86]. After 8 months of median follow-up, six out of eight patients improved in terms of inflammation control. Mesquida et al. reported on the long-term efficacy and safety of tocilizumab for refractory uveitisassociated macular edema [10]. All their patients were refractory to CDMARD and at least one bDMARD prior to initiation of tocilizumab. Uveitis diagnoses were BSC $(n=3)$, JIA-associated uveitis $(n=3)$, and idiopathic panuveitis $(n=1)$. After a 15 -month follow up, no serious adverse events were observed. Mean central foveal thickness improved significantly from 550 to 274 $\mu \mathrm{m}$ at month 12 . Visual acuity also significantly improved from 0.67 to 0.4 at month 12 . The same group published 24 months results of quiescent uveitis patients with recalcitrant uveitic macular edema (ME), treated with TCZ [9]. Diagnoses included patients with BSC, JIA-associated uveitis, idiopathic panuveitis, sympathetic ophthalmia, and ankylosing spondylitis. Sustained inflammatory remission was maintained in all 12 patients. However, an attempt to withdraw TCZ could only be made in five of them because of systemic disease and perceived high risk of visual loss. All five patients in whom TCZ therapy was withdrawn, ME relapsed within 1 to 3 months after cessation. A re-challenge with $\mathrm{TCZ}$ infusions in those patients induced recovery. In the study, tocilizumab was generally well-tolerated except one case of dose-dependent neutropenia and another case of pneumonia [9].

In addition to these encouraging results in small case series and retrospective studies with relatively small number of patients, the first prospective randomized clinical trial STOP-Uveitis was conducted to assess the safety and efficacy of tocilizumab in NIU [11]. STOPUveitis was a 6-month study of 37 patients treated with one of two intravenous doses (either 4 or $8 \mathrm{mg}$ per $\mathrm{kg}$ ) of tocilizumab for posterior NIU. The majority of the cases were of idiopathic origin (28/37 patients) but subjects who had uveitis secondary to Vogt-KoyanagiHarada syndrome, sarcoidosis, punctate inner choroiditis, and ABD were also included. Only $20-25 \%$ of the study population had history of immunomodulatory therapy usage. Two patients developed low absolute neutrophil counts (ANC) after receiving the first 
infusion of tocilizumab; one normalized before the second infusion while the other subject exited the study. No ocular adverse events related to the study drug were observed. The STOP-Uveitis study demonstrated that the therapy was well-tolerated and associated with a reduction in vitreous haze and cystoid macular edema at both doses (Fig. 4) [11].

Tocilizumab: dose and route of administration The approved starting dose of TCZ differs in various regions of the world. TCZ also has two approved systemic modes of administration: intravenous (IV) and subcutaneous (SC). In the USA, induction therapy employs $4 \mathrm{mg} / \mathrm{kg}$ monthly IV regimen followed by step up to $8 \mathrm{mg} / \mathrm{kg}$ monthly based on therapeutic response. However, in Europe, the approved initiating and maintenance dose is $8 \mathrm{mg} / \mathrm{kg}$ IV monthly, titrated to $4 \mathrm{mg} / \mathrm{kg}$ if side effects occur.

$\mathrm{SC}$ route of administration has important advantages such as providing more convenient route of administration, including self-application at home, negating the requirement for and associated health care costs of intravenous access, and frequent clinic visits. The efficacy of the SC route over IV route was evaluated in several studies. Two randomized, double-masked, 24-week comparative, phase 3 studies demonstrated the non-inferiority of TCZ-SC to TCZ-IV: SUMMACTA in Europe and MUSASHI in Japan [87-89]. SUMMACTA compared TCZ-SC $162 \mathrm{mg}$ every week to TCZ-IV $8 \mathrm{mg} / \mathrm{kg}$ every 4 weeks, and MUSASHI compared TCZ-SC $162 \mathrm{mg}$ every 2 weeks or TCZ-IV $8 \mathrm{mg} / \mathrm{kg}$ every 4 weeks, showed safety and non-inferior efficacy of TCZ-SC. BREVACTA, another randomized, double-masked, 24-week comparative trial in the USA, evaluated $162 \mathrm{mg}$ TCZ-SC every 2 weeks versus placebo [88]. BREVACTA showed that TCZ-SC was superior to placebo. These studies led to the approval of the subcutaneous formulation and the dosing recommendations in the European Union and the USA. Consistent with the respective intravenous labels, in the EU, the approved starting dose for TCZ-SC is $162 \mathrm{mg}$ every week, with a possible decrease in dosage frequency to every 2 weeks. In the USA, the starting dose for TCZ-SC is 162 mg every 2 weeks, with a possible increase in dosing to every week, based on clinical response approved [90]. In summary, TCZ-SC appears to be as effective as TCZ-IV with comparable safety.

Tocilizumab: safety and pre-administration evaluation The safety of TCZ in patients with RA has been evaluated in several phase 3 and 4 RCTs [37, 50, 53, 80, 82, $87,88]$. Infections such as nasopharyngitis, upper respiratory tract infections, pneumonia, and cellulitis were the most common. Other major adverse events were gastrointestinal perforations (GIPs), neutropenia, and malignancies. Laboratory test abnormalities were also reported with TCZ therapy, including elevated liver

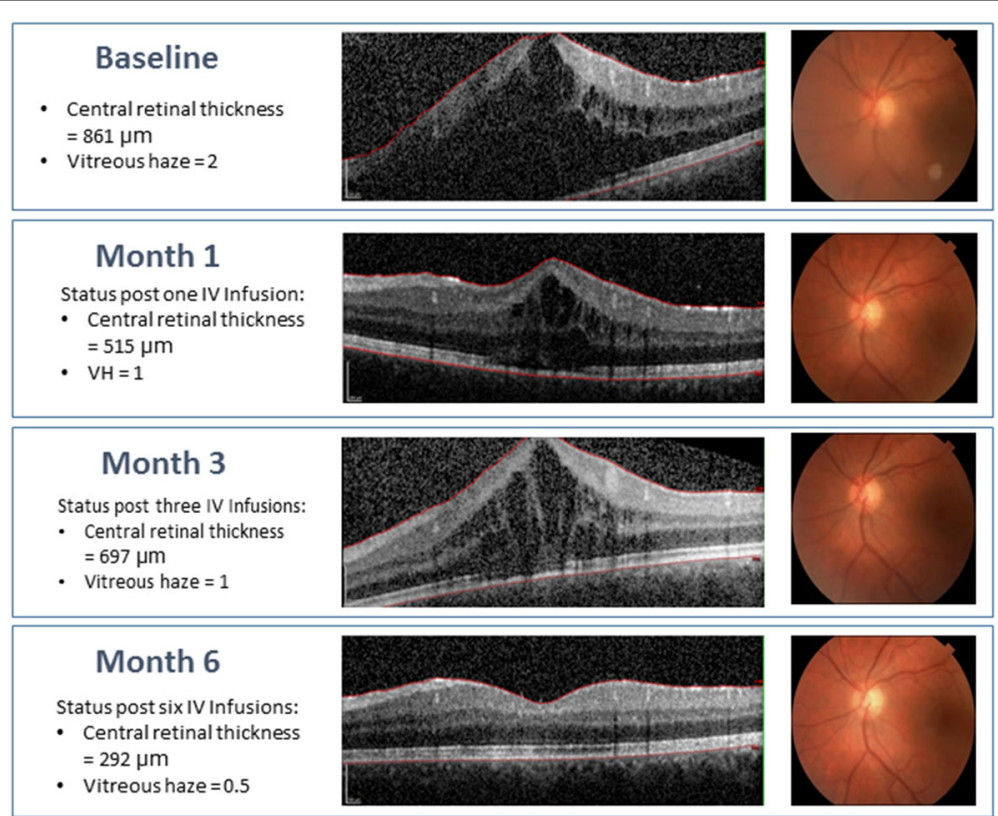

Fig. 4 A case of an 18-year-old male subject with idiopathic panuveitis and macular edema who was a subject in the STOP-Uveitis Study, demonstrating changes in vitreous haze and central retinal thickness after treatment with intravenous infusions of 4 mg/kg tocilizumab. The subject was not on any other therapy while he was being treated with tocilizumab. [Adapted from Sepah YJ, Sadiq MA, Chu DS, et al. Primary (month-6) outcomes of the STOP-uveitis study: Evaluating the safety, tolerability, and efficacy of tocilizumab in patients with non-infectious uveitis. Am J Ophthalmology 2017; 183:71-80.] 
enzyme levels, decreased neutrophil counts, and change in lipid levels.

The real-world studies, in line with the data from RCTs, also found higher incidence of GIPs in patients treated with TCZ than in those treated with other biologics or cDMARDs [91, 92]. For every 1000 patients treated with TCZ per year, between one and two additional GIPs might be expected to occur compared with those treated with other TNF inhibitors [93]. In particular, the risk for lowerintestinal perforations (LIPs) seems to be higher in patients with a history of diverticulitis [91, 92].

Malignancy and neutropenia are two additional concerns for patients receiving TCZ. The risk for malignancy is potentially greater in patients with RA who use immunosuppressive agents. The current hypothesis is that inflammatory activity associated with RA drives the increased lymphoma risk. Additionally, some evidence suggests that patients with RA treated with biologics are at increased risk for malignancy, specifically non-melanoma skin cancers, compared with the general population [94]. Despite these inferences, the analysis of the data from phase 3 trials and long-term extension studies did not demonstrate increased risk for overall or site-specific malignancies above the risk expected in patients with RA. The overall malignancy rate observed in tocilizumab, all-exposure population was higher than that in the general population but was consistent with that expected in the RA population and in the geographic regions studied [16].

Data for neutropenia incidence with TCZ are divergent. De Benedetti et al. reported neutropenia incidences as high as $57 \%$ in a cohort of 112 patients with JIA [95]. A dose-dependent effect on neutropenia-onset was observed in RCTs, where the incidence of neutropenia at 8 $\mathrm{mg} / \mathrm{kg}$ was almost twice as observed at $4 \mathrm{mg} / \mathrm{kg}[37,49]$. In a retrospective cohort study, TCZ was associated with a higher incidence of neutropenia compared with abatacept and infliximab. However, the increased incidence of neutropenia did not result in a higher risk for severe infections [96]. Also, data from these trials confirm that grade 4 neutropenia $(<0.5 \mathrm{ANC} \times 109 / \mathrm{l})$ is extremely uncommon.

Adverse events reported in RCTs with TCZ in pediatric age group, treated for JIA, were similar to the adult group and included infections, neutropenia, and abnormalities in liver function test results [95, 97]. Notably, no or very few cases of macrophage activation syndrome (MAS), which resolved, were reported in those studies. On the other hand, a patient registry post-marketing surveillance (PMS) in Japan, which was conducted to investigate the safety and effectiveness of TCZ in realworld clinical settings, reported slightly higher adverse event rates than those reported in clinical trials of TCZ for systemic JIA [98]. This dissimilarity was attributed to the fact that RCTs had excluded patients with concurrent medical or surgical conditions; or concomitant diseases of the nervous, renal, endocrine, or hepatic systems.

All this data from RCTs and cohort studies highlights the need for careful patient selection when treating with anti-IL-6 agents (i.e., exclusion of individuals with previous diverticulitis, exclusion of infections such as tuberculosis, fungal, etc.). Patients should be closely monitored for the development of signs and symptoms of infection during and after treatment. In order to ensure safe use of TCZ in daily practice, physicians and patients should also be aware that, under TCZ, conditions such as GIP, MAS (in pediatrics) may occur with mild symptoms only and careful examination and testing are crucial.

\section{Newer IL-6 inhibitors}

TCZ was launched as the first biologic drug targeting IL-6 in 2010, which provided a strong alternative to anti-TNF$\alpha$ agents. Clinical success of TCZ was encouraging, which led pharmaceutical industry to undertake research in discovering other IL-6 blocking pathways. Currently, several IL-6/IL-6R inhibitors are under investigation in various phases of different studies (Table 1). These molecules can be broadly divided into two categories:

Targeting IL-6 with Sirukumab, Siltuximab, Olokizumab, Clazakizumab, and EBI-031

\section{Targeting IL-6R with Sarilumab and ALX-0061}

Sarilumab Sarilumab (Kevzara ${ }^{\circ}$, Sanofi Genzyme, Regeneron Pharmaceuticals, USA) is a fully human antiIL-6R $\alpha \mathrm{mAb}$ that blocks both classic and trans-signaling pathway by binding to membrane-bound as well as soluble forms of IL-6R $\alpha$, with higher affinity as compared to tocilizumab.

Sarilumab received its USFDA approval in May 2017 for treatment of RA. It is indicated for the treatment of rheumatoid arthritis and is undergoing clinical trials for use in the management of posterior segment non-infectious uveitis. In the SATURN study, in patients with non-infectious uveitis, reductions in vitreous haze and steroid dosing were seen in treated patients. Visual acuity and central macular thickness also improved with a $200 \mathrm{mg}$ dose administered subcutaneously every 2 weeks. This drug targets a specific inflammatory mediator and has been associated with fewer side effects than other available therapies. Neutropenia and elevated alanine amino-transferase levels were reported as adverse events [99].

Sirukumab Sirukumab (Plivensia ${ }^{\circ}$, Janssen Biologics, Horsham, PA GlaxoSmithKline, UK) is a fully human mAB that binds IL-6. US Food and Drug Administration's Arthritis Advisory Committee did not recommend 
Table 1 Features of various IL-6 inhibitors - available and investigational, [in RA]

\begin{tabular}{|c|c|c|c|c|c|}
\hline & Target & Structure & $\begin{array}{l}\text { Dose and route of } \\
\text { administration }\end{array}$ & $\begin{array}{l}\text { Current indications } \\
\text { (FDA approved) }\end{array}$ & Potential indications \\
\hline Tocilizumab & sIL-6R mIL-6R & Recombinant humanized & $\begin{array}{l}4-8 \mathrm{mg} / \mathrm{kg} \text { IV q4wk } \\
162 \mathrm{mg} \text { SC q2wk/q4wk }\end{array}$ & RA, JIA, GCA & $\begin{array}{l}\text { Takayasu's arteritis, Behçet's disease, adult } \\
\text { onset Still's disease, multicentric Castleman's } \\
\text { disease (approved in Japan), relapsing } \\
\text { polychondritis, Cogan's disease, inflammatory } \\
\text { myositis, lupus, NIU }\end{array}$ \\
\hline Sarilumab & sIL-6R mIL-6R & Human mAb & 200 mg SC q2wk & RA & RA, NIU \\
\hline Sirukumab & $\| \mathrm{L}-6$ & Human mAb & $\begin{array}{l}\text { FDA approval denied } \\
\text { for RA }\end{array}$ & $\mathrm{n} / \mathrm{a}$ & - \\
\hline Siltuximab & IL-6 & Chimeric & $\begin{array}{l}12 \mathrm{mg} / \mathrm{kg} \\
\mathrm{q} 3 \mathrm{wk}\end{array}$ & $\begin{array}{l}\text { Castleman's } \\
\text { disease }\end{array}$ & $\begin{array}{l}\text { Multiple myeloma, currently no studies } \\
\text { in NIU }\end{array}$ \\
\hline Clazakizumab & IL-6 & Humanized mAb & 25-200 mg SC q4wk & Not FDA approved & Renal transplant, psoriatic arthritis, RA \\
\hline Olokizumab & $\| \mathrm{L}-6$ & Humanized mAb & $64 \mathrm{mg} \mathrm{SC}$ q2wk/q4wk & Not FDA approved & RA \\
\hline ALX-0061 & sIL-6R mIL-6R & $\begin{array}{l}\text { Nanobody } \\
\text { (heavy chain-only) }\end{array}$ & $\mathrm{n} / \mathrm{a}$ & Not FDA approved & SLE, RA \\
\hline MEDI 5117 & $\| \mathrm{L}-6$ & Human mAb & $\mathrm{n} / \mathrm{a}$ & Not FDA approved & - \\
\hline
\end{tabular}

$R A$ rheumatoid arthritis, JIA juvenile idiopathic arthritis, GCA giant cell arteritis, NIU non-infectious uveitis, SC subcutaneous, $I V$ intravenous, $n / a$ not available, qnwk once every " $n$ " number of weeks

sirukumab for the treatment of adults with active rheumatoid arthritis (RA). While the committee unanimously agreed that there is substantial evidence of efficacy of sirukumab for the treatment of these patients, the safety profile is not adequate to support its approval. In phase 3 SIRROUND-D study, the primary adverse events were related to immunosuppression, consistent with those found with other DMARDS; however, there was a trend of increased overall mortality with sirukumab compared with placebo [100]. Out of a total 35 deaths in study patients, 34 occurred in those taking sirukumab. Prominent causes of death were major cardiac events, infection, and malignancy. Increased risk for serious infection was associated with sirukumab; opportunistic infection and tuberculosis were both reported with its use.

Siltuximab Siltuximab (Sylvant ${ }^{\circ}$ ) is a chimeric (humanmurine) $\mathrm{mAB}$ that targets IL-6. It is approved for the treatment of patients with multicentric Castleman's disease by FDA. It can neutralize the IL- 6 effect in a number of human malignancies, reducing cancer-related cachexia and anorexia. In a phase I, open-label study, no dose-related or cumulative toxicity was apparent across all disease indications. A dose of $12 \mathrm{mg} / \mathrm{kg}$ every 3 weeks was recommended on the basis of the high response rates in Castleman's disease and the sustained CRP suppression. Most common drug-related adverse event was thrombocytopenia (25\%). Randomized studies are ongoing in Castleman's disease and multiple myeloma [101]. There are no studies at present to indicate its use in NIU.

Olokizumab Olokizumab (R-Pharma, UCB) is a humanized $\mathrm{mAB}$ that acts on site- 3 of IL- 6 and prevents binding of IL-6 to its signaling co-receptor gp130, thereby blocking the assembly of IL-6 signaling complex. It was found effective in a 12-week phase $2 \mathrm{~b}$ study in RA patients who were refractory to TNF inhibitors. OKZ treatment, at several doses, demonstrated similar efficacy to TCZ across multiple endpoints. Most adverse events were mild or moderate and comparable between OKZ and TCZ treatment groups. OKZ produced significantly greater reductions in DAS28 (CRP) from baseline at week 12 compared with placebo. Reported adverse events were consistent with the safety profile expected of this class of drug without newer safety concerns [102]. No studies at present suggest the use of olokizumab in NIU.

Clazakizumab Clazakizumab (Vitaeris ${ }^{\circ}$, ALD518, Bothell, USA) is also a humanized anti-IL-6 agent. It showed greater affinity and prolonged half-life in comparison to olokizumab. Clazakizumab proved clinical efficacy by achieving its primary endpoint in treating RA patients, refractory to MTX; however, dose-response effect was lacking. Patients achieved significant improvements in disease activity, including higher rates of remission, as compared with patients receiving only MTX. Clazakizumab treatment groups showed a higher rate of serious adverse events (range 8.3 to 13.6\%), compared with 3.3\% in MTX group. Pharmacological effects of IL-6 blockade showed consistency with levels of IL-6 measured in laboratory [103]. Clazakizumab also has not been evaluated in the management of NIU.

\section{Conclusion}

\section{Future of IL-6 inhibition}

Various studies in the literature show association of inflammatory disorders like uveitis, retinal vascular 
occlusions, and diabetic macular edema with increased levels of IL-6. Such data provides a clue to possible area of research and clinical trials targeting these diseases using IL-6 inhibitors. In a pre-clinical study, EAU was treated using intraocular IL-6 locally; this points toward the development of intravitreal IL- 6 therapy which can help to avoid associated systemic side-effects.

IL-6 provides an alternative to TNF- $\alpha$ inhibition in the management of NIU. Tocilizumab and secukinumab have shown promising results over established biologics. Various other IL-6 inhibitors are under study and could provide similar therapeutic potentials with added advantages.

It has been recognized that the levels of IL- 6 were raised in other ocular vascular diseases such as retinal vein occlusion and diabetic macular edema. There are also cases of NIU with macular edema that responded well to tocilizumab therapy but returned after withdrawal of therapy, only to resolve again when treatment was restarted. Further studies are needed to understand the role of IL-6 inhibitors in non-uveitic macular edema, where anti-VEGF therapy remains the standard of care.

Subcutaneous administration has been evaluated in various studies and has been found non-inferior to IV route. Thus, SC administration can further decrease infusion-related inconvenience and expenditure. Once the newer molecules of IL-6 inhibitors, which target only the trans-cellular pathway, become more established, as we gain experience in their use, complications of IL-6 inhibition such as sepsis can be minimized.

\section{Perspective}

In the current era of pharmacotherapy for uveitis, we can theoretically target TNF, IL-1, IL-12/IL-23, IL-6, IL17, CTLA4, CD20, etc.-various cytokines that have been identified in the serum and eyes of patients with different types of uveitis. There may be several agents that aim at particular cytokines. As clinicians and scientists gain deeper understanding of the pathophysiology of uveitis, we may be able to target individual cytokines for each disease in each patient, moving toward the goal of precision medicine. As part of future therapeutic plans, patients may undergo biomarker profiling, to be performed on serum and ocular fluids for example, prior to the initiation of any therapeutic plans. Based on specific biomarker(s) identified for specific patients, we can employ monotherapy (i.e., IL-6 inhibitor) or combination therapy (i.e., IL-1 and IL- 6 antagonists or anti-TNF and anti-IL-17 pharmacologic agents) to manage the ocular diseases, being vigilant not to acquire excessive immunosuppression.

In summary, increasing number of studies are showing that IL-6 inhibitors can be very effective biologic agents in the management of NIU. Moreover, additional role of
IL-6 inhibition may be realized in the future, possibly opening a newer approach to the management of retinal vascular diseases and non-uveitic macular edema.

\section{Abbreviations}

IL-6: Interleukin 6; IV: Intravenous; SC: Subcutaneous; NIU: Non-infectious uveitis; RVO: Retinal vein occlusion; DME: Diabetic macular edema; VEGF: Vascular endothelial growth factor; TNF: Tumor necrosis factor; mAB: Monoclonal antibody; TLR: Toll-like receptors; PAMPs: Pathogenassociated molecular patterns; DAMPs: Damage-associated molecular patterns; CRP: C-reactive protein; ZIP: Zinc importer; RANKL: Receptor activator of nuclear factor kappa-B ligand; JAK: Janus kinase; STAT3: Signal transducers and activators of transcription 3; NMO: Neuromyelitis optica; TGF: Transforming growth factor; IFN-y: Interferon gamma; EAU: Experimental autoimmune uveitis; PG: Prostaglandin; TCZ: Tocilizumab; OKZ: Olokizumab; RA: Rheumatoid arthritis; SLE: Systemic lupus erythematosus; GCA: Giant cell arteritis; JIA: Juvenile idiopathic arthritis; MTX: Methotrexate; BSCR: Birdshot chorioretinopathy; BD: Behcet's disease; CDMARDs: Conventional diseasemodifying antirheumatic drugs; bDMARDs: Biological disease-modifying antirheumatic drugs; MAS: Macrophage activation syndrome; USFDA: United States Food and Drug Administration; GIP: Gastrointestinal perforation; LIP: Lower intestinal perforation; Treg: T regulatory cells; pg: Picogram

Acknowledgements

Not applicable.

Availability of data and material

Not applicable.

\section{Authors' contributions}

SK, MH3, EV, SH, MH2, CP, NN, RA, AT, DV, YJS, and QDN conceptualized the manuscript. SK, MH3, and EV designed the manuscript. All authors read and approved the final manuscript.

\section{Authors' information}

QDN is a recipient of a Physician Scientist Award from Research to Prevent Blindness, New York, NY, and serves on the Scientific Advisory Board for AbbVie, Bayer, Genentech, Regeneron, and Santen, among others. QDN also chaired the Steering Committee for the RISE and RIDE studies and was on the Steering Committee for the VISTA Study, and other studies sponsored by Genentech and Regeneron.

\section{Funding}

None.

Ethics approval and consent to participate

Not applicable.

\section{Consent for publication}

Not applicable.

\section{Competing interests}

The authors declare that they have no competing interests.

\section{Author details}

${ }^{1}$ Byers Eye Institute, Spencer Center for Vision Research, Stanford University, 2370 Watson Court, Suite 200, Palo Alto, CA 94303, USA. ²Department of Ophthalmology, All India Institute of Medical Sciences Bhopal, Bhopal, Madhya Pradesh, India. ${ }^{3}$ Department of Ophthalmology, School of Medicine, Gazi University, Ankara, Turkey. ${ }^{4}$ University of Texas Southwestern Medical Center, Dallas, TX, USA. ${ }^{5}$ Department of Ophthalmology, Hospital Universitario de León, León, Spain. ${ }^{6}$ University of Nebraska, Lincoln, USA.

Received: 4 March 2019 Accepted: 2 August 2019

Published online: 16 September 2019

\section{References}

1. Tode J et al (2017) Intravitreal injection of anti-Interleukin (IL)-6 antibody attenuates experimental autoimmune uveitis in mice. Cytokine 96:8-15

2. Horai R, Caspi RR (2019) Microbiome and autoimmune uveitis. Front Immunol 10:232 
3. Mesquida M et al (2017) Targeting interleukin-6 in autoimmune uveitis. Autoimmunity reviews 16(10):1079-1089

4. Kishimoto T (2010) IL-6: from its discovery to clinical applications. International immunology 22(5):347-352

5. Ataie-Kachoie $P$ et al (2013) Inhibition of the IL-6 signaling pathway: a strategy to combat chronic inflammatory diseases and cancer. Cytokine \& growth factor reviews 24(2):163-173

6. Lin, P. (2015) Targeting interleukin-6 for noninfectious uveitis. Clinical ophthalmology (Auckland, N.Z.) 9, 1697-1702.

7. Perez VL et al (2004) Elevated levels of interleukin 6 in the vitreous fluid of patients with pars planitis and posterior uveitis: the Massachusetts eye \& ear experience and review of previous studies. Ocular immunology and inflammation 12(3):193-201

8. Adan A et al (2013) Tocilizumab treatment for refractory uveitis-related cystoid macular edema. Graefe's archive for clinical and experimental ophthalmology = Albrecht von Graefes Archiv fur klinische und experimentelle Ophthalmologie 251(11):2627-2632

9. Mesquida, M. et al. (2018) Twenty-four month follow-up of tocilizumab therapy for refractory uveitis-related macular edema. Retina (Philadelphia, Pa.) 38 (7), 1361-1370.

10. Mesquida $\mathrm{M}$ et al (2014) Long-term effects of tocilizumab therapy for refractory uveitis-related macular edema. Ophthalmology 121(12):2380-2386

11. Sepah YJ et al (2017) Primary (Month-6) outcomes of the STOP-Uveitis study: evaluating the safety, tolerability, and efficacy of tocilizumab in patients with noninfectious uveitis. American Journal of Ophthalmology 183:71-80

12. Kang $S$ et al (2015) Therapeutic uses of anti-interleukin-6 receptor antibody. International immunology 27(1):21-29

13. Calabrese LH, Rose-John S (2014) IL-6 biology: implications for clinical targeting in rheumatic disease. Nature reviews. Rheumatology 10(12):720-727

14. Hoge, J. et al. (2013) IL-6 controls the innate immune response against Listeria monocytogenes via classical IL-6 signaling. Journal of immunology (Baltimore, Md.: 1950) 190 (2), 703-711.

15. Matzinger, P. (2002) The danger model: a renewed sense of self. Science (New York, N.Y.) 296 (5566), 301-305.

16. Rubbert-Roth A et al (2016) Malignancy rates in patients with rheumatoid arthritis treated with tocilizumab. RMD open 2(1):e000213-2015-000213 eCollection 2016

17. Devaraj $S$ et al (2011) C-reactive protein induces release of both endothelial microparticles and circulating endothelial cells in vitro and in vivo: further evidence of endothelial dysfunction. Clinical chemistry 57(12):1757-1761

18. Jensen, L.E. and Whitehead, A.S. (1998) Regulation of serum amyloid A protein expression during the acute-phase response. The Biochemical journal 334 ( Pt 3) (Pt 3), 489-503.

19. Nemeth, E. et al. (2004) Hepcidin regulates cellular iron efflux by binding to ferroportin and inducing its internalization. Science (New York, N.Y.) 306 (5704), 2090-2093.

20. Ishibashi T et al (1989) Human interleukin 6 is a direct promoter of maturation of megakaryocytes in vitro. Proceedings of the National Academy of Sciences of the United States of America 86(15):5953-5957

21. Hashizume $M$ et al (2008) IL-6 trans-signalling directly induces RANKL on fibroblast-like synovial cells and is involved in RANKL induction by TNFalpha and IL-17. Rheumatology (Oxford, England) 47(11):1635-1640

22. Nakahara $\mathrm{H}$ et al (2003) Anti-interleukin-6 receptor antibody therapy reduces vascular endothelial growth factor production in rheumatoid arthritis. Arthritis and Rheumatism 48(6):1521-1529

23. Gillespie EF et al (2012) Interleukin-6 production in CD40-engaged fibrocytes in thyroid-associated ophthalmopathy: involvement of Akt and NF-kappaB. Investigative ophthalmology \& visual science 53(12):7746-7753

24. Brenne AT et al (2002) Interleukin-21 is a growth and survival factor for human myeloma cells. Blood 99(10):3756-3762

25. Heinrich PC et al (2003) Principles of interleukin (IL)-6-type cytokine signalling and its regulation. The Biochemical journal 374(Pt 1):1-20

26. Taga T, Kishimoto T (1997) Gp130 and the interleukin-6 family of cytokines. Annual Review of Immunology 15:797-819

27. Rose-John S (2012) IL-6 trans-signaling via the soluble IL-6 receptor: importance for the pro-inflammatory activities of IL-6. International journal of biological sciences 8(9):1237-1247

28. Seong GJ et al (2009) TGF-beta-induced interleukin-6 participates in transdifferentiation of human Tenon's fibroblasts to myofibroblasts. Molecular vision 15:2123-2128
29. Sugaya S et al (2011) Regulation of soluble interleukin-6 (IL-6) receptor release from corneal epithelial cells and its role in the ocular surface. Japanese journal of ophthalmology 55(3):277-282

30. Tanaka T et al (2011) Anti-interleukin-6 receptor antibody, tocilizumab, for the treatment of autoimmune diseases. FEBS letters 585(23):3699-3709

31. Tanaka T et al (2011) PDLIM2 inhibits T helper 17 cell development and granulomatous inflammation through degradation of STAT3. Science signaling 4(202):ra85

32. Narazaki M et al (1993) Soluble forms of the interleukin- 6 signal-transducing receptor component gp130 in human serum possessing a potential to inhibit signals through membrane-anchored gp130. Blood 82(4):1120-1126

33. Schmitz J et al (2000) SOCS3 exerts its inhibitory function on interleukin-6 signal transduction through the SHP2 recruitment site of gp130. The Journal of biological chemistry 275(17):12848-12856

34. Kishimoto T et al (1995) Interleukin-6 family of cytokines and gp130. Blood 86(4):1243-1254

35. Scheller J et al (2011) The pro- and anti-inflammatory properties of the cytokine interleukin-6. Biochimica et biophysica acta 1813(5):878-888

36. Genovese, M.C. et al. (2015) Sarilumab Plus methotrexate in patients with active rheumatoid arthritis and inadequate response to methotrexate: results of a phase III study. Arthritis \& rheumatology (Hoboken, N.J.) 67 (6), 1424-1437.

37. Smolen JS et al (2014) Sirukumab, a human anti-interleukin-6 monoclonal antibody: a randomised, 2-part (proof-of-concept and dose-finding), phase II study in patients with active rheumatoid arthritis despite methotrexate therapy. Annals of the Rheumatic Diseases 73(9):1616-1625

38. Jego $\mathrm{G}$ et al (2003) Plasmacytoid dendritic cells induce plasma cell differentiation through type I interferon and interleukin 6. Immunity 19(2): 225-234

39. Diehl SA et al (2012) IL-6 triggers IL-21 production by human CD4+ T cells to drive STAT3-dependent plasma cell differentiation in B cells. Immunology and cell biology 90(8):802-811

40. Dienz, O. and Rincon, M. (2009) The effects of IL-6 on CD4 T cell responses. Clinical immunology (Orlando, Fla.) 130 (1), 27-33.

41. Chihara $\mathrm{N}$ et al (2011) Interleukin 6 signaling promotes anti-aquaporin 4 autoantibody production from plasmablasts in neuromyelitis optica. Proceedings of the National Academy of Sciences of the United States of America 108(9):3701-3706

42. Kawano $\mathrm{M}$ et al (1988) Autocrine generation and requirement of BSF-2/IL-6 for human multiple myelomas. Nature 332(6159):83-85

43. Atreya R et al (2000) Blockade of interleukin 6 trans signaling suppresses T-cell resistance against apoptosis in chronic intestinal inflammation: evidence in crohn disease and experimental colitis in vivo. Nature medicine 6(5):583-588

44. Korn T et al (2009) IL-17 and Th17 Cells. Annual Review of Immunology 27: 485-517

45. Bettelli E et al (2006) Reciprocal developmental pathways for the generation of pathogenic effector TH17 and regulatory T cells. Nature 441(7090):235-238

46. Kimura A, Kishimoto T (2010) IL-6: regulator of Treg/Th17 balance. European journal of immunology 40(7):1830-1835

47. Neveu, W.A. et al. (2009) IL-6 is required for airway mucus production induced by inhaled fungal allergens. Journal of immunology (Baltimore, Md.: 1950) 183 (3), 1732-1738.

48. Diehl S et al (2000) Inhibition of Th1 differentiation by IL-6 is mediated by SOCS1. Immunity 13(6):805-815

49. Kremer JM et al (2011) Tocilizumab inhibits structural joint damage in rheumatoid arthritis patients with inadequate responses to methotrexate: results from the double-blind treatment phase of a randomized placebocontrolled trial of tocilizumab safety and prevention of structural joint damage at one year. Arthritis and Rheumatism 63(3):609-621

50. Emery $P$ et al (2008) IL-6 receptor inhibition with tocilizumab improves treatment outcomes in patients with rheumatoid arthritis refractory to antitumour necrosis factor biologicals: results from a 24-week multicentre randomised placebo-controlled trial. Annals of the Rheumatic Diseases 67(11):1516-1523

51. Strand V et al (2018) Patient-reported outcomes from a randomized phase III trial of sarilumab monotherapy versus adalimumab monotherapy in patients with rheumatoid arthritis. Arthritis research \& therapy 20(1):129-018-1614-z

52. Jones $\mathrm{G}$ et al (2010) Comparison of tocilizumab monotherapy versus methotrexate monotherapy in patients with moderate to severe rheumatoid arthritis: the AMBITION study. Annals of the Rheumatic Diseases 69(1):88-96 
53. Choy E et al (2018) Subcutaneous tocilizumab in rheumatoid arthritis: findings from the common-framework phase 4 study programme TOZURA conducted in 22 countries. Rheumatology (Oxford, England) 57(3):499-507

54. Hirano T et al (1987) Human B-cell differentiation factor defined by an antipeptide antibody and its possible role in autoantibody production. Proceedings of the National Academy of Sciences of the United States of America 84(1):228-231

55. Hamzaoui K et al (2002) Cytokine profile in Behcet's disease patients Relationship with disease activity. Scand J Rheumatol 31(4):205-210

56. Mesquida $M$ et al (2014) Interleukin-6 blockade in ocular inflammatory diseases. Clinical and experimental immunology 176(3):301-309

57. Waage A et al (1989) The complex pattern of cytokines in serum from patients with meningococcal septic shock. Association between interleukin 6, interleukin 1, and fatal outcome. The Journal of experimental medicine 169(1):333-338

58. Yoshimura T et al (2009) Involvement of Th17 cells and the effect of anti-IL-6 therapy in autoimmune uveitis. Rheumatology (Oxford, England) 48(4):347-354

59. Haruta $\mathrm{H}$ et al (2011) Blockade of interleukin-6 signaling suppresses not only th17 but also interphotoreceptor retinoid binding protein-specific Th1 by promoting regulatory $T$ cells in experimental autoimmune uveoretinitis. Investigative ophthalmology \& visual science 52(6):3264-3271

60. Zahir-Jouzdani F et al (2017) Interleukin-6 participation in pathology of ocular diseases. Pathophysiology 24(3):123-131

61. Murray PI et al (1990) Aqueous humor interleukin-6 levels in uveitis. Investigative ophthalmology \& visual science 31(5):917-920

62. de Boer JH et al (1992) Analysis of IL-6 levels in human vitreous fluid obtained from uveitis patients, patients with proliferative intraocular disorders and eye bank eyes. Current eye research 11(Suppl):181-186

63. Kramer $\mathrm{M}$ et al (2007) Serum cytokine levels in active uveitis and remission. Current eye research 32(7-8):669-675

64. Kishimoto, T. and Ishizaka, K. (1974) Regulation of antibody response in vitro. 8. Multiplicity of soluble factors released from carrier-specific cells. Journal of immunology (Baltimore, Md.: 1950) 112 (5), 1685-1697.

65. Funatsu $\mathrm{H}$ et al (2003) Vitreous levels of interleukin-6 and vascular endothelial growth factor are related to diabetic macular edema. Ophthalmology 110(9):1690-1696

66. Noma $\mathrm{H}$ et al (2009) Vitreous levels of interleukin-6 and vascular endothelial growth factor in macular edema with central retinal vein occlusion. Ophthalmology 116(1):87-93

67. Suzuki $Y$ et al (2011) Expression profiles of cytokines and chemokines in vitreous fluid in diabetic retinopathy and central retinal vein occlusion. Jpn J Ophthalmol 55(3):256-263

68. Sadaka A, Giuliari GP (2012) Proliferative vitreoretinopathy: current and emerging treatments. Clin Ophthalmol 6:1325-1333

69. Leonardi AA et al (2004) Multiple cytokine evaluation in tears of allergic conjunctivitis patients by Multi-Cytokine Bead Assay. Investigative Ophthalmology \& Visual Science 45:U308-U308

70. Higuchi A et al (2011) IL-6 induction in desiccated corneal epithelium in vitro and in vivo. Mol Vis 17:2400-2406

71. Carnt NA et al (2012) Association of single nucleotide polymorphisms of interleukins-1 beta, -6 , and $-12 \mathrm{~B}$ with contact lens keratitis susceptibility and severity. Ophthalmology 119(7):1320-1327

72. Rojas $\mathrm{M}$ et al (2010) Role of IL-6 in angiotensin II-induced retinal vascular inflammation. Invest Ophthalmol Vis Sci 51(3):1709-1718

73. Lewis AC (2013) Interleukin-6 in the pathogenesis of posterior capsule opacification and the potential role for interleukin- 6 inhibition in the future of cataract surgery. Med Hypotheses 80(4):466-474

74. Tobler A et al (1992) Glucocorticoids downregulate gene expression of GMCSF, NAP-1/IL-8, and IL-6, but not of M-CSF in human fibroblasts. Blood 79(1):45-51

75. Griffin MO et al (2010) Tetracyclines: a pleitropic family of compounds with promising therapeutic properties. Review of the literature. American journal of physiology. Cell physiology 299(3):C539-C548

76. Sapadin AN, Fleischmajer R (2006) Tetracyclines: nonantibiotic properties and their clinical implications. Journal of the American Academy of Dermatology 54(2):258-265

77. Gu Y et al (2011) Chemically modified tetracycline-3 (CMT-3): a novel inhibitor of the serine proteinase, elastase. Pharmacological research 64(6):595-601

78. Yokota $S$ et al (2012) Efficacy, safety and tolerability of tocilizumab in patients with systemic juvenile idiopathic arthritis. Therapeutic advances in musculoskeletal disease 4(6):387-397
79. Yao $X$ et al (2014) Targeting interleukin-6 in inflammatory autoimmune diseases and cancers. Pharmacology \& therapeutics 141(2):125-139

80. Bijlsma JWJ et al (2016) Early rheumatoid arthritis treated with tocilizumab, methotrexate, or their combination (U-Act-Early): a multicentre, randomised, double-blind, double-dummy, strategy trial. Lancet (London, England) 388(10042):343-355

81. Burmester GR et al (2016) Tocilizumab in early progressive rheumatoid arthritis: FUNCTION, a randomised controlled trial. Annals of the Rheumatic Diseases 75(6):1081-1091

82. Gabay $C$ et al (2013) Tocilizumab monotherapy versus adalimumab monotherapy for treatment of rheumatoid arthritis (ADACTA): a randomised, double-blind, controlled phase 4 trial. Lancet (London, England) 381(9877):1541-1550

83. Muselier A et al (2011) Efficacy of tocilizumab in two patients with anti-TNFalpha refractory uveitis. Ocul Immunol Inflamm 19(5):382-383

84. Hirano T et al (2012) A case of Behcet's disease treated with a humanized anti-interleukin-6 receptor antibody, tocilizumab. Modern rheumatology 22(2):298-302

85. Tappeiner $\mathbf{C}$ et al (2012) Is tocilizumab an effective option for treatment of refractory uveitis associated with juvenile idiopathic arthritis? The Journal of rheumatology 39(6):1294-1295

86. Papo $\mathrm{M}$ et al (2014) Tocilizumab in severe and refractory non-infectious uveitis. Clinical and experimental rheumatology 32(4 Suppl 84):S75-S79

87. Burmester GR et al (2014) A randomised, double-blind, parallel-group study of the safety and efficacy of subcutaneous tocilizumab versus intravenous tocilizumab in combination with traditional disease-modifying antirheumatic drugs in patients with moderate to severe rheumatoid arthritis (SUMMACTA study). Annals of the Rheumatic Diseases 73(1):69-74

88. Kivitz A et al (2014) Subcutaneous tocilizumab versus placebo in combination with disease-modifying antirheumatic drugs in patients with rheumatoid arthritis. Arthritis care \& research 66(11):1653-1661

89. Ogata A et al (2014) Phase III study of the efficacy and safety of subcutaneous versus intravenous tocilizumab monotherapy in patients with rheumatoid arthritis. Arthritis care \& research 66(3):344-354

90. Abdallah $\mathrm{H}$ et al (2017) Pharmacokinetic and pharmacodynamic analysis of subcutaneous tocilizumab in patients with rheumatoid arthritis from 2 randomized, controlled trials: SUMMACTA and BREVACTA. Journal of clinical pharmacology 57(4):459-468

91. Strangfeld A et al (2017) Risk for lower intestinal perforations in patients with rheumatoid arthritis treated with tocilizumab in comparison to treatment with other biologic or conventional synthetic DMARDs. Annals of the Rheumatic Diseases 76(3):504-510

92. Xie, F. et al. (2016) Brief Report: risk of gastrointestinal perforation among rheumatoid Arthritis patients receiving tofacitinib, tocilizumab, or other biologic treatments. Arthritis \& rheumatology (Hoboken, N.J.) 68 (11), 2612-2617.

93. Monemi S et al (2016) Incidence of Gastrointestinal perforations in patients with Rheumatoid arthritis treated with tocilizumab from clinical trial, postmarketing, and real-world data sources. Rheumatology and therapy 3(2):337-352

94. Wolfe F, Michaud K (2007) Biologic treatment of rheumatoid arthritis and the risk of malignancy: analyses from a large US observational study. Arthritis and Rheumatism 56(9):2886-2895

95. De Benedetti F et al (2012) Randomized trial of tocilizumab in systemic juvenile idiopathic arthritis. The New England journal of medicine 367(25): 2385-2395

96. Espinoza F et al (2017) Biologic Disease-modifying antirheumatic drug (bDMARD)-induced neutropenia: a registry from a retrospective cohort of patients with rheumatic diseases treated with 3 classes of intravenous bDMARD. The Journal of rheumatology 44(6):844-849

97. Yokota $S$ et al (2014) Longterm safety and effectiveness of the antiinterleukin 6 receptor monoclonal antibody tocilizumab in patients with systemic juvenile idiopathic arthritis in Japan. The Journal of rheumatology 41(4):759-767

98. Yokota S et al (2016) Tocilizumab in systemic juvenile idiopathic arthritis in a real-world clinical setting: results from 1 year of postmarketing surveillance follow-up of 417 patients in Japan. Annals of the Rheumatic Diseases 75(9):1654-1660

99. Heissigerova J et al (2019) Efficacy and Safety of sarilumab for the treatment of posterior segment noninfectious uveitis (SARIL-NIU): the phase 2 SATURN study. Ophthalmology 126(3):428-437 
100. Takeuchi T et al (2017) Sirukumab for rheumatoid arthritis: the phase III SIRROUND-D study. Annals of the Rheumatic Diseases 76(12):2001-2008

101. Kurzrock R et al (2013) A phase I, open-label study of siltuximab, an anti-IL-6 monoclonal antibody, in patients with B-cell non-Hodgkin lymphoma, multiple myeloma, or Castleman disease. Clinical cancer research : an official journal of the American Association for Cancer Research 19(13):3659-3670

102. Genovese MC et al (2014) Efficacy and safety of olokizumab in patients with rheumatoid arthritis with an inadequate response to TNF inhibitor therapy: outcomes of a randomised Phase llb study. Annals of the Rheumatic Diseases 73(9):1607-1615

103. Weinblatt, M.E. et al. (2015) The efficacy and safety of subcutaneous clazakizumab in patients with moderate-to-severe rheumatoid arthritis and an inadequate response to methotrexate: results from a multinational, phase $\mathrm{ll} b$, randomized, double-blind, placebo/active-controlled, doseranging study. Arthritis \& rheumatology (Hoboken, N.J.) 67 (10), 2591-2600

\section{Publisher's Note}

Springer Nature remains neutral with regard to jurisdictional claims in published maps and institutional affiliations.

\section{Submit your manuscript to a SpringerOpen ${ }^{\circ}$ journal and benefit from:}

- Convenient online submission

- Rigorous peer review

- Open access: articles freely available online

- High visibility within the field

Retaining the copyright to your article

Submit your next manuscript at $\boldsymbol{\wedge}$ springeropen.com 